\title{
Aetiological Factors of Urogenital Fistula and the Treatment Outcome of Patients with Urogenital Fistula Admitted in Rajshahi Medical College Hospital, Rajshahi
}

\author{
Sharmin Razzaque ${ }^{1}$, Nazmun Nahar $^{2}$, Sahela Jesmin $^{3}$, Hasina Akhter ${ }^{4}$
}

\begin{abstract}
Urogenital fistulas, majority of which are of vesicovaginal fistulas are commonly caused by prolong obstructed labor and is one of the worst complications of childbirth and poor obstetric care. With the advancement of health care delivery system aetiology of urogenital fistula is also changing in our country. The objective of this study is to create awareness about urogenital fistula, to evaluate the aetiology, profile of the patients and outcome of surgical repair in RMCH. It was a cross-sectional type of observational study having descriptive component of a total 68 cases of urogenital fistula admitted in the department of Obstetrics and Gynaecology, RMCH over a period of one year and six months from January 2009 to July 2010. The incidence among patients admitted in Obstetrics and Gynae was $0.45 \%$ and among Gynae patient's incidence was $1.1 \%$. Majority of the patients were young primipara, short stature and malnourished, coming from lower socio-economic condition of rural areas. Obstructed labour 21(30.8\%) was the most common cause of urogenital fistula, followed by gynecological surgeries mainly hysterectomies $19(27.3 \%)$, corrosive application $7(10 \%)$ a rare cause but was found in high rate in this study. A total no of 50 patients underwent surgery. Overall success rate was $46(92 \%)$ and functionally failed with a failure in $4(8 \%)$ cases. The etiology urogenital fistula is preventable and all types of urinary fistula can be repair. Improvement in maternity care in rural areas, easy approach to specialist care and better training of staff in instrumental deliveries may help to decrease the incidence of these fistulas.
\end{abstract}

Key Words: Urogenital fistula, vesicovaginal fistula, prolonged labour.

TAJ 2016; 29: No-2: 11-15

\section{Introduction}

An abnormal communication between urinary and genital tract is termed urogenital fistula. The commonest type of genitourinary fistula is vesicovaginal fistula (VVF). With advance obstetric care these fistula are rare in industrialized world, but they continue to plaque women in the third world. Globally about 3.5 million women are

1 Junior Consultant, Obs \& Gynae, Durgapur Upazilla Health Complex, Rajshahi.

${ }^{2}$ Assistant Professor, Department of Obs \& Gynae, Rajshahi Medical College, Rajshahi.

${ }^{3}$ Associate Professor \& Head, Department of Obs \& Gynae, Rajshahi Medical College, Rajshahi.

${ }_{4}^{4}$ Professor and Head, Department of Obs \& Gynae, Barind Medical College, Rajshahi. 
living with genitourinary fistula; a miserable condition. ${ }^{1}$ An incidence of 1-2 per 1000 deliveries has estimated worldwide, with an annual incidence of upto 50.000 to $100,000 .^{2}$ According to UNFPA \& Engender Health, the number of women living with fistula is estimated to be 1.69 per 1000 ever married women. The aetiology of genitourinary fistula broadly categorized into congenital and acquired. Acquired fistula is divided into obstetrical, surgical, post radiation, extension of disease process, foreign body, chemical burn, accidents. The etiology of urogenital fistula is dependent on the availability and adequacy of obstetric care, malignancy, rates and types of pelvic surgery that a woman was undergone. In developing countries, obstetric trauma is more likely to be the cause, whereas in developed countries, gynecological procedures and radiotherapy are the main contributors. ${ }^{3}$ Obstetrical fistula can arise from (a) pressure necrosis (b) direct injury during delivery. ${ }^{4}$ In neglected obstructed labour the anterior vaginal wall, bladder base and urethra are compressed between the fetal head and the posterior pubis. This area undergoes pressure necrosis, and within 3-10 days post partum, the tissue slough off. Average length of labor 3.8 days. ${ }^{5}$ Lacks of privacy in hospital, objection from families in different attitude of husband leads to prolong labor, encourage obstructed labor. But recently the incidence of genitourinary fistula following gynecological surgery specially hysterectomy has increased in this continent also. The reason is that gynecological surgeries are being performed by health professionals at peripheral hospitals who are not properly trained. ${ }^{6}$. The success of repair depends on the site of fistula and its extent. Expertise of the surgeon and the choice of technique play important role in the outcome. The present study focuses on the incidence, etiology, the sociodemographic character related to development of urogenital fistula and its outcome at a tertiary hospital. This is a preliminary study; the result of this cross-sectional study may help to take steps through a concerted effort, which includes prevention and treatment so that the issue of urogenital fistula in Bangladesh can easily be address.

\section{Material and Methods}

This was a cross-sectional type study of patients admitted with signs of incontinence of urine in gynecological ward of Rajshahi Medical College Hospital. Study period ranged from January 2009 to December 2010. For this permission was taken from institute's ethical committee. Patient complaining of incontinence of stool due to injury to the genital tract during the process of labour of any cause are excluded. . A detailed history has taken to pin point the causal factor. This included respondent's personal information, socioeconomic condition, past Obstetrical and medical history, pattern of medical care and problem faced by the women suffering from urogenital fistula. Data were collected by standard questionnaire. All patients were examined in the outpatients and in the operating theater. The assessment included the woman`s general physical condition, size, site and number of fistula, amount of scarring of fistulous margins or stenosis of the vagina. Detailed examination was done including examination under anesthesia, speculum examination, catheter test, three swab tests. A complete urinalysis was also done and if needed cystoscopy was also done in some patient prior to surgery. After the assessment of the patient appropriate operative measure were taken. All fistulas were repaired by flap splitting method. Grafts like labial tissue used in large fistulas. All the results were noted in predesigned history sheet. After removal of the catheter the patients were advised to drink plenty of liquid and to void frequently. The patients were discharged from the hospital 24-48 hours after removal of the catheter. Surgery was considered to be successful if patient can hold urine and there is no leakage of urine in between the act of voiding after removal of catheter and before discharge from the hospital. 


\section{Results}

In this study 68 patients included during the period of one year and six month (Jan 2009-July 2010). About 6065 patient got admitted in the gynecology ward of Rajshahi Medical College Hospital in this period, yielding an incidence of UGF to be $1.1 \%$. Age of patients ranged from 16 to 64 years (Mean $\pm \mathrm{SD}=38 \pm 12.4$ years). Parity ranged from para 1 to 6, mostly (36.7\%) were young primipara. Obstetrical complications mainly obstructed labor (52.9\%) was the most common cause for the development Urogenital fistula, followed by gynecological surgeries, mainly hysterectomies (22, 32.3\%) as shown in Table-1, etiology distribution. The duration of symptom ranged from 3 days to $>10$ years. Vesico-vaginal fistula was the commonest and constituted $86.7 \%$, in most of these trigone was involved due to its anatomical vulnerability. About $51.4 \%$ of patients have small size fistula, $20.5 \%$ medium and $16 \%$ large fistula. In $13 \%$ cases there was extensive fistula and $11 \%$ patients had extensive fibrosis in surrounding tissue where as $36 \%$ patients had no fibrosis Out of 68 patients with urogenital fistulae, 8 patients with small fistulae healed conservatively with continuous catheter drainage where 3 patients could not be operated because they suffered from carcinoma of cervix in terminal stages. 5 patients were advised to come after 3 months because of presence of unhealthy tissues around the fistulae. Therefore, 50 patients underwent surgery. The commonest approach used was transvaginal $45(90 \%)$ and 5 patients (10\%) were repaired through abdominal procedure used was layer closure. Labial graft was given in 4(8\%) patient. Among 50 patients successful repair was done in 46 cases and the success rate was $92 \%(n=50)$. In this study failure rate was $8 \%$. Further attempts were required due to leakage.

Table 1 : Aetiology distribution $(\mathrm{n}=68)$

\begin{tabular}{lcc}
\hline Causative factors & $\begin{array}{c}\text { Number of } \\
\text { patient }\end{array}$ & Percentage \\
\hline (A) Obstetrical causes & & \\
Prolonged labor (SVD) & 21 & 30.8 \\
\hline
\end{tabular}

\begin{tabular}{|c|c|c|}
\hline $\begin{array}{ll}\text { Obstructed } & \text { labor }\end{array}$ & 2 & 2.9 \\
\hline (Craniotomy instruments) & 2 & 2.9 \\
\hline $\begin{array}{l}\text { IProlonged labor (NVD with } \\
\text { Ventose) }\end{array}$ & 11 & 16.1 \\
\hline $\begin{array}{ll}\text { lObstructed } & \text { labor } \\
\text { (Caesarean section) } & \end{array}$ & & \\
\hline (B) Gynecological causes & Total $=36$ & $52.94 \%$ \\
\hline Hysterectomies & 19 & 27.3 \\
\hline Malignancy & 3 & 4.4 \\
\hline (C) Trauma & Total $=22$ & $32.3 \%$ \\
\hline RTA & 1 & 1.4 \\
\hline Iatrogenic & 2 & 2.9 \\
\hline & Total $=3$ & $4.3 \%$ \\
\hline (D) Corrosive & 7 & 10 \\
\hline $\begin{array}{l}\mathrm{n}: \text { Number of patient } \\
\text { SVD : Spontaneous vaginal del } \\
\text { NVD : Normal vaginal del } \\
\text { Table } 2 \text { : Medical facto } \\
\\
\text { development (n }\end{array}$ & $\begin{array}{l}\text { very } \\
\text { S related } \\
=68)\end{array}$ & fistula \\
\hline Medical factors & $\begin{array}{c}\text { Number of } \\
\text { patients }\end{array}$ & Percentage \\
\hline Maternal height & & \\
\hline $\begin{array}{l}\text { Short stature }(<145 \mathrm{~cm}) \\
\text { Normal stature }(>145 \mathrm{~cm}) \\
\text { Nutritional status }\end{array}$ & $\begin{array}{l}33 \\
35\end{array}$ & $\begin{array}{l}48.5 \\
51.4\end{array}$ \\
\hline $\begin{array}{l}\text { Below average }(\mathrm{BMI}<19) \\
\text { Average }(\mathrm{BMI} 19-25) \\
\text { Above average }(\mathrm{BMI}>25) \\
\text { Antenatal care }\end{array}$ & $\begin{array}{c}38 \\
26 \\
4\end{array}$ & $\begin{array}{c}55.8 \\
38 \\
5.8\end{array}$ \\
\hline $\begin{array}{l}\text { No antenatal check up } \\
\text { Regular antenatal check up } \\
\text { Place of delivery }\end{array}$ & $\begin{array}{l}40 \\
28\end{array}$ & $\begin{array}{l}58.8 \\
41.1\end{array}$ \\
\hline $\begin{array}{l}\text { Home } \\
\text { Hospital } \\
\text { Mode of delivery }\end{array}$ & $\begin{array}{l}21 \\
15\end{array}$ & $\begin{array}{c}30.8 \\
22\end{array}$ \\
\hline Prolonged labor (SVD) & 21 & 30.8 \\
\hline $\begin{array}{l}\text { Prolonged labor (NVD with } \\
\text { Ventose) }\end{array}$ & 2 & 2.9 \\
\hline $\begin{array}{l}\text { Obstructed labor (VD with } \\
\text { Craniotomy) }\end{array}$ & 2 & 2.9 \\
\hline $\begin{array}{l}\text { Delivery with Caesarean } \\
\text { section } \\
\text { Fetal size }\end{array}$ & 11 & 16.1 \\
\hline Large (> 4 kg) & 15 & 22 \\
\hline Average (2.5- $3.5 \mathrm{~kg})$ & 36 & 52.9 \\
\hline $\mathrm{SGA}(<2.5 \mathrm{~kg})$ & 17 & 25 \\
\hline
\end{tabular}


$\mathrm{n}$ : Number of patient

BMI: Body Mass Index

NVD: Normal Vaginal Delivery

SGA: Small for Gestational Age

SVD: Spontaneous Vaginal Deliver

VD: Vaginal Delivery

\section{Fig Outcome of the study}

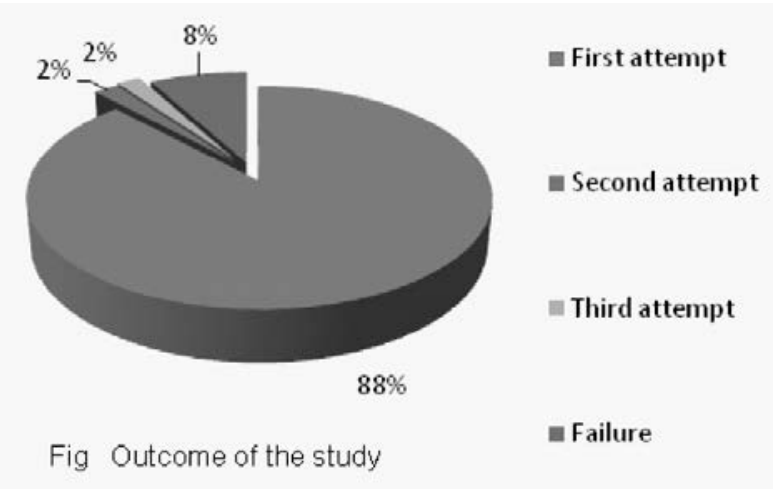

\section{Discussion}

Despite its devastating impact on the lives of girls and women, urogenital fistula is still largely neglected in the developing world. It has remained a hidden condition, because it affects some marginalized members of the population. The true incidence of urogenital fistula is unknown as many women do not reach hospital, and continue to be neglected by their husbands ostracized from society. The incidence of urogenital fistula among all admitted patients of Obstetric and Gynae Department was $0.45 \%$ and among Gynae patients the incidence was $1.1 \%$. This may be a true low incidence in the country or may be due to under reporting, as in Pakistan. ${ }^{3}$ Majority of the patients in this study come from low socioeconomic group which is very similar to other study in our country. ${ }^{7}$ Majority of the patients (39.7\%) in this study belonged to the age group of 31-40 years and $39.6 \%$ patients were of less than 30 years of age as the retrospective study in Ghana from 1997-1999. Another study done in DMCH in 2005 also revealed similar data that young primiparas are more vulnerable. ${ }^{8}$ Majority of the patients (36.7\%) developed fistula during their first child birth similar to other study. ${ }^{7}$ About $48 \%$ patients had height between 131-145 cm and another 7\% patients had height $<130 \mathrm{~cm}$. There was large difference in the etiology of the urogenital fistula around the world. The study of Lee et al found that more than $80 \%$ of genitourinary fistulas arose from gynecological surgery for benign disease. Uncomplicated total abdominal hysterectomy accounted for more than $70 \%$ of these surgeries, $10 \%$ cases were with associated obstetrical trauma and $5 \%$ following radiotherapy and oncosurgery ${ }^{6}$. In this study $52.94 \%$ (36/68) of urogenital fistula arising out of obstetrical complication, 21 obstructed labor, 4 instrumental deliveries and 11 lower segment caesarean section. The study conducted by Ghazala Sadiq from Pakistan showed incidence of urogenital fistula because of obstructed labor was $54.55 \%{ }^{3}$ In contrast to the study of Uprety DK of Nepal, the etiology of fistulas in this series were related to obstructed labor in 39\% that develop after first child birth. ${ }^{1}$ In Pushpa Srichand study obstetrical complications were responsible for $88 \%$ cases and gynecological surgeries for $9 \%$ cases. ${ }^{6}$ Among the surgical interference a dissimilarity found that LUCS was the most common surgical interference. Percentage of craniotomy was very negligible and Ventouse delivery also very low (2.9\%) as destructive surgery is not commonly practiced now a days. Emergency caesarean section done in very late stage of obstructed labor when ischemic tissue injury has already taken place may lead to VVF. This is the reason why $11(16 \%)$ patients had fistula following emergency caesarean section. Urogenital fistula due to corrosive application was found in this study which was absent in other study. In 7 (10\%) patients the cause of fistula was corrosive or herbal medicine application for correction of urogenital prolapse suggested by quack. This reflects that this practice of corrosive application is quite common in the north-west region of Bangladesh. It is very disappointed as these fistulas are large and extensive involving the bladder mucosa. Only 2 patient, successful repairs can be done with labial grafting. Urogenital fistula following malignancy was found in 3 (4.4\%) patient mostly due to carcinoma cervix of very 
advanced stage, where no surgery could be done referred for radiotherapy. The Regarding the types of fistula VVF was found commonest in $86.7 \%$, a finding common to other workers ${ }^{8}$. Though most of the $51.4 \%$ of the fistulas were less than $2 \mathrm{~cm}$, which was favorable for successful repair but 4.4\% patient had vaginal stenosis. $90 \%$ fistula was repaired through vaginal route. In this study 8 patients had very large fistula and graft was placed in 4 patients, 1 had failed after 2 attempt of repair. The timing of the fistula repair is one of the contentious aspects of fistula management. The success rate in this study was $88 \%$ at primary attempt comparable to other study. ${ }^{3}$ Overall success rate of this study in Rajshahi Medical College Hospital, in Bangladesh over a period of 1 year 6 month is $92 \%$ which is very encouraging and correlates well with recently published series.

\section{Conclusion}

Urogenital fistula is still a major health problem in our country with obstetric trauma as a leading cause. This study has shown that best results are obtained when repair of urogenital fistulae is carried out under optimal condition. Good operative technique is important and it includes proper exposure of fistula, excision of fistula tract, wide mobilization of vaginal mucosa around the fistula, secure closure of bladder mucosa, approximation without any tension and adequate bladder drainage are mandatory with use of interposition of flaps when needed. A multidisciplinary approach including a gynecologist, urologist and at times a psychiatrist gives better results. Although we showed that we can achieve good success rates of $92 \%$ but however, prevention remains an achievable goal. It is also important to create awareness in the society.

\section{References}

1. Uprety DK, Subedi S,Budhathoki B, Regmi MC: Vesico-vaginal Fistula At Tertiary Center in Estern Nepal.J Nepal Med Assoc 2008:47(171):120-2

2. Maqsud Mahliqa: Obstetric Fistula Prevention in South Asia an Overview 2007.

3. Ghazala Sadiq, Md Sadiq, Nadra Sultana (July 18, 2008): Obstetric Trauma is the Cause of Urogenital Fistula.

4. Hussain, A (1985): Vesico-Vaginal Fistula A Review Bangladesh Journal of Obstetrics and Gynaecology Vol: 20-32.

5. Medscape general medicine 5 (3), 2003 (c) 2003 Medscape: obstructed labor and the Vesico- vaginal fistula

6. Pushpa Srichand Sachdev, N Hassan, Abbasi Mustafa, Chandra Madhu; J Ayub Medical College Abbottabad 2009; p21-24.

7. Banu Laila Arjumand, AClincal Study on Genito Urinary Fistula,1997

8. Fatima Nusrat, Post-operative complication and problems in fistula patients after repair of fistula in Bangladesh National Fistula Centre of DMCH, 2005. 